\title{
Does Quality of Care Differ When HIV Patients Are Treated by Non-Specialist and Specialist HIV Healthcare Providers in Developed Countries? A Systematic Narrative Review
}

\author{
Bossakara Sokhom1, Emmanuel Okpo ${ }^{2,3^{*}}$, Ivan Tonna ${ }^{4}$, Amudha Poobalan ${ }^{3}$ \\ ${ }^{1}$ College of Life Sciences and Medicine, University of Aberdeen, Aberdeen, Scotland, UK \\ ${ }^{2}$ Department of Public Health, National Health Service (NHS) Grampian, Aberdeen, Scotland, UK \\ ${ }^{3}$ Division of Applied Health Sciences, University of Aberdeen, Aberdeen, Scotland, UK \\ ${ }^{4}$ Ward 111, Emergency Care Centre, Aberdeen Royal Infirmary, Foresterhill, Aberdeen, Scotland, UK \\ Email: *emmanuel.okpo@nhs.net
}

Received 30 July 2015; accepted 25 August 2015; published 28 August 2015

Copyright (C) 2015 by authors and Scientific Research Publishing Inc.

This work is licensed under the Creative Commons Attribution International License (CC BY).

http://creativecommons.org/licenses/by/4.0/

(c) (i) Open Access

\section{Abstract}

Introduction: In developed countries, HIV care is mostly provided by trained specialist healthcare professionals. Due to the increasing demand for HIV care, pressure on healthcare providers to reduce cost and the current global economic constraints, many developed countries are searching for alternative HIV care models. This review aims to consider whether HIV treatment and care can be provided as effectively and safely by doctors and nurses with no HIV-specialist training compared to those with HIV-specialist training. Methods: Three electronic bibliographic databases MEDLINE, EMBASE and the Cochrane Library were searched for studies conducted between January 1996 and March 2015. Manual searches of reference lists of all relevant reports retrieved from the electronic databases were conducted. All comparative studies examining the quality of HIV care provided by different types of healthcare providers in developed countries were included. Results: Nine observational studies involving 27,015 patients were included in the review. Eight studies were conducted in the USA and one study in Switzerland. Healthcare providers with HIVrelated expertise and or training and those without HIV-related expertise or training who collaborated with providers with HIV-related expertise and or training outperformed other healthcare providers in many virological, immunological and ART-related outcomes. Conclusion: This review found moderate quality evidence that HIV care can be provided effectively by non-HIV spe-

\footnotetext{
"Corresponding author.
} 
cialists if they have access to HIV specialists or experts for advice and support.

Keywords

HIV/AIDS, Healthcare Providers, Quality of Care, Developed Countries, Systematic Review

\section{Introduction}

In the last two decades, the availability and wide use of combination antiretroviral therapy (cART) in developed countries has enabled people living with HIV/AIDS (PLWHA) to live increasingly longer and healthier lives. PLWHA who start cART early are expected to receive treatment for up to 50 years [1]-[3]. Care of PLWHA in developed countries is mainly provided by clinicians and nurses who have expertise in HIV medicine in specialist care centres. For instance, in the USA and the United Kingdom, patients who are diagnosed with HIV are referred to infectious disease or HIV specialists for further care and treatment. Yet, as more PLWHA are diagnosed and treated the need for these providers will increase. However, due to the current economic constraints in many developed countries, the present treatment model of mainly relying on HIV specialists for care and treatment of PLWHA will make it more difficult to respond to the increasing demand of HIV care. In order to sustain the gains achieved in the fight against HIV/AIDS, an alternative model of care is needed to help offset the anticipated burden on the current healthcare systems while maintaining the same high quality of HIV care.

Currently, some low- and middle-income countries (LMICs) have turned to models of care such as taskshifting and decentralisation of HIV care [4] [5]. Decentralisation of HIV care outside of the hospital settings provided by non-HIV specialists has also been implemented in other LMICs and found to be as beneficial as HIV care provided in hospital settings [6].

In developed countries very few studies have examined the effectiveness of task shifting of HIV care to meet the needs of the increasing number of PLWHA and offset the rising costs of care. This systematic literature review aims to report on the evidence of the quality of HIV care provided by different types of healthcare professionals in developed countries in the cART era.

\section{Methods}

Protocol for this review was developed a priori following the methodology outlined by the Centre for Reviews and Dissemination [7].

\subsection{Study Inclusion and Exclusion Criteria}

Randomized and controlled clinical trials, cohorts, case control, cross-sectional studies and interrupted time series with comparison groups that investigated the quality of HIV care provided by different types of healthcare professionals were included in this review. Editorials, comments, letters, clinical guidelines or reviews were excluded. For this review, healthcare providers were defined as health professionals providing medical and nursing care and not ancillary care to PLWHA. HIV specialists were defined as clinicians who have received specialised HIV training from accredited institutions or those who have self-identified as HIV specialists. Studies that involved healthcare providers who provided ancillary or social care were excluded. Because treatment and care of PLWHA has evolved rapidly, only studies that were carried out from 1996 onwards when cART became widely and readily available in developed countries were considered.

All PLWHA aged 18 or older receiving antiretroviral therapy (ART) were included. Participants who required specialty care services other than for their HIV (e.g. adults with mental illnesses) were excluded. Study settings were developed countries classified as members of the Organization for Economic Cooperation and Development (OECD) in 2014 as these countries are socioeconomically comparable and have healthcare systems that are fairly representative of other developed nations.

Commonly measured outcomes in HIV clinical care studies were employed to assess the quality of HIV care [8] including reduction in HIV viral load; CD4 cell count; use of ART; hospitalization and length of hospital stay; use of appropriate prophylaxis; adherence to ART; appropriate screenings and vaccinations; patient satis- 
faction of care; and non-HIV related interactions due to HIV care and treatment.

\subsection{Search Strategy}

MEDLINE, EMBASE and the Cochrane Library [9] were systematically searched for studies published between 1996 and 2015 limiting to English articles only.

A robust search strategy was developed using relevant text words and MeSH or Emtree headings for healthcare providers, clinicians, doctors, nurses, HIV/AIDS, ART, OECD countries, which were combined by using Boolean operators such as "AND" and "OR".

Additional articles were identified by hand searching the reference lists of all relevant texts. All citations were imported into Refworks bibliographical manager.

\subsection{Data Extraction and Analysis}

BS, EO and IT screened the titles and abstracts of all the citations to identify potentially eligible articles using $a$ priori inclusion and exclusion criteria. The three authors independently screened and critically appraised the full-text reports of all potentially eligible studies using a piloted eligibility checklist. Data were then extracted from all eligible studies using a piloted data extraction form adapted from the Cochrane Collaboration guidelines [10]. Disagreements were discussed and resolved through consensus. A narrative synthesis of data was carried out as a meta-analysis was not appropriate due to the heterogeneity of the included studies.

\subsection{Quality Assessment/Risk of Bias}

BS and EO independently assessed the quality of the included studies using the Effective Public Health Practice Project (EPHPP) Quality Assessment Tool for Quantitative Studies [11]. The tool assesses studies against selection bias, study design, confounders, blinding, data collection methods, attrition, intervention integrity and data analyses, which it provides "strong", "moderate" or "weak" quality rating. Potential important confounding variables such as patients' age, sex, race/ethnicity and case mix that were identified in other HIV intervention studies were also evaluated [12] [13]. Uncertainties in quality assessment were resolved through arbitration with another reviewer (IT).

\section{Results}

\subsection{Search Results}

2,327 citations from electronic searches and 65 additional reports from manual search of the reference lists of relevant reports were identified. After removing duplicates and irrelevant reports, nine studies with 27,015 participants were included in the review. The majority of the excluded reports were review articles or studies that focused on care settings rather than healthcare professionals. Figure 1 shows the PRISMA flow diagram.

\subsection{Characteristics of Included Studies}

The characteristics and findings of the nine included studies are summarized in Table 1. All nine studies were non-randomized studies: two were retrospective cohort studies [14] [15], four were prospective cohort studies [16]-[19] and three were cross-sectional studies [20]-[22].

All but one of the included studies were carried out in the USA. The non-USA study was conducted in Switzerland. Eight studies were conducted in outpatient settings [14]-[18] [20]-[22] and one study was carried out in an inpatient hospital setting [19]. Two of the studies in the USA were conducted in a treatment network in New York [14] and California [15], three were conducted with patients within existing research studies across the 48 contiguous states [16] [19] [21], two were done in federally funded HIV clinics across the USA [18]-[22] and one was done using public and medical records of women receiving government medical care benefits in New York [20]. The Swiss study was conducted in a teaching outpatient clinic and general practices in urban Zurich [17].

There was considerable variation across the studies in terms of definition and training of the different HIV care providers such as infectious disease (ID), HIV experts, HIV specialists, and generalist; and the comparisons 


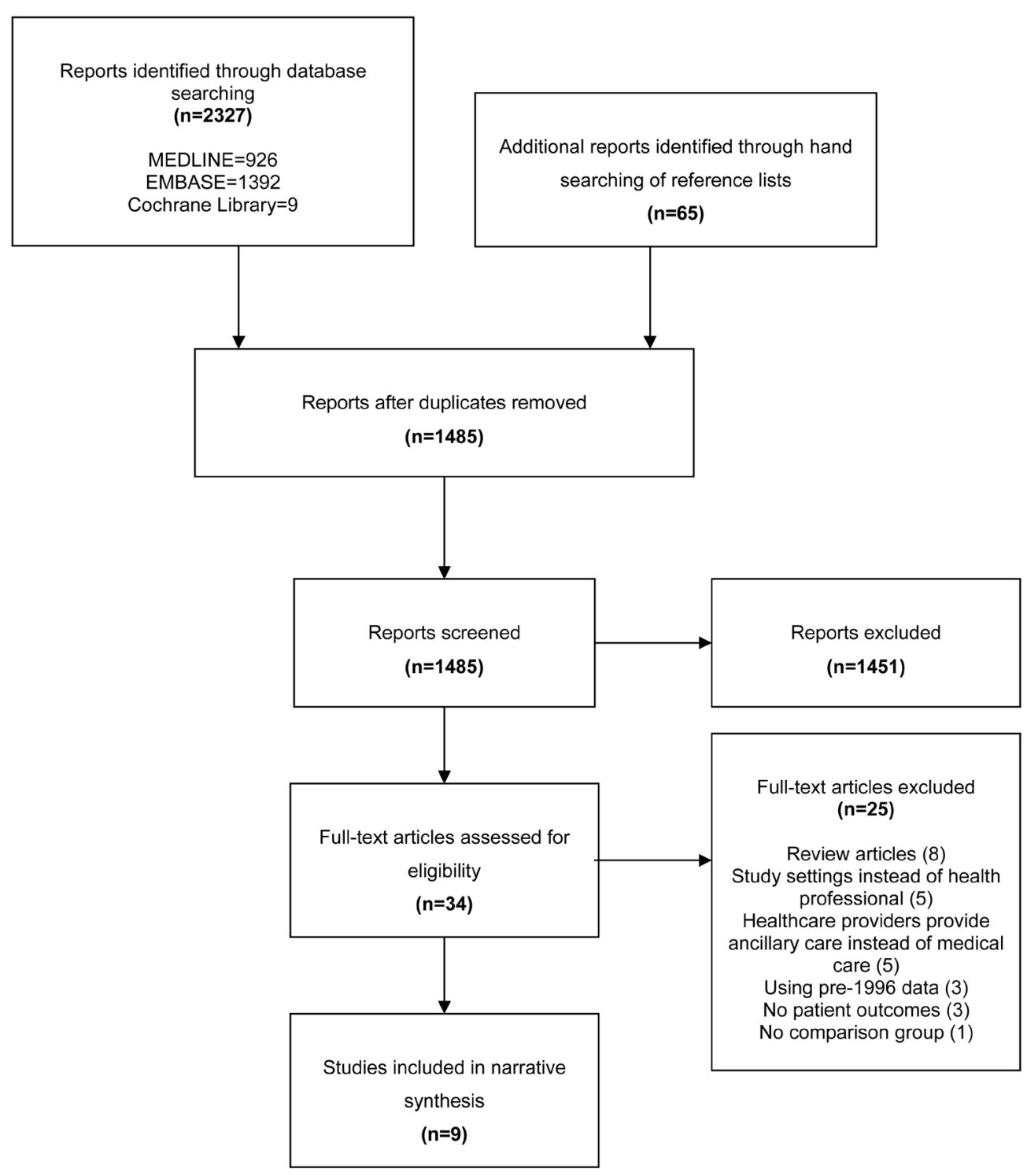

Figure 1. Study selection flow diagram.

between these different providers.

\subsection{Quality Assessment}

Five studies were considered to have "strong" overall quality rating [14]-[18], while three studies were rated "moderate" [19] [20] [22] and one study was rated "weak" [21] (Table 2).

All of the included studies controlled for at least four of the six important confounding variables: age, sex, race/ethnicity, HIV risk, insurance status and case mix (Table 3).

\subsection{Reported Outcomes}

Twenty-five different outcomes were reported across the nine studies (Table 4).

\subsubsection{Viral Load}

Five studies [14] [15] [17] [18] [22] measured viral load; of which, three studies show significant differences in viral loads depending on the care provided by different healthcare personnel. 
Table 1. Summary of included studies' characteristics and findings.

\begin{tabular}{|c|c|c|c|c|c|c|c|}
\hline $\begin{array}{l}\text { Author/ } \\
\text { Publication } \\
\text { year }\end{array}$ & Country & Study Design & $\begin{array}{l}\text { Study } \\
\text { population/ } \\
\text { setting }\end{array}$ & Intervention & \multicolumn{2}{|r|}{ Outcomes } & Notes \\
\hline $\begin{array}{l}\text { Chu } \\
2010 \\
(14)\end{array}$ & $\begin{array}{c}\text { New York, } \\
\text { USA }\end{array}$ & $\begin{array}{c}\text { Retrospective } \\
\text { cohort study. } \\
\text { Data } \\
\text { collected } \\
\text { for years } \\
2005-2008\end{array}$ & $\begin{array}{l}\text { Non-pregnant HIV } \\
\text { positive adults } 18+ \\
\text { years on cART in } \\
\text { community-based } \\
\text { primary care } \\
\text { network (CB) } \\
(\mathrm{n}=178) \text { vs. a } \\
\text { large tertiary care } \\
\text { center and } \\
\text { teaching hospital } \\
\text { (HB) }(\mathrm{n}=237)\end{array}$ & $\begin{array}{c}\text { CB: } \\
\text { non-HIV-expert } \\
\text { PCP in } \\
\text { collaboration } \\
\text { with accredited } \\
\text { HIV specialists } \\
\text { (all general } \\
\text { internal/family } \\
\text { medicine-trained) } \\
\text { vs. HB: ID-trained } \\
\text { clinicians }\end{array}$ & \multicolumn{2}{|r|}{$\begin{array}{c}\text { CB } \mathbf{H B} \\
\text { adj OR 1.22, 95\% CI } 0.41 \text { to } 3.63 .\end{array}$} & $\begin{array}{l}\text { Fewer patients } \\
\text { initiating cART } \\
\text { than needed for } \\
\text { statistical } \\
\text { significance. } \\
\text { Data were } \\
\text { adjusted for } \\
\text { patients' } \\
\text { characteristics. }\end{array}$ \\
\hline $\begin{array}{l}\text { Gardner } \\
2002(21)\end{array}$ & USA & $\begin{array}{c}\text { Cross-section } \\
\text { al analysis. } \\
\text { Data } \\
\text { collected } \\
\text { for years } \\
\text { 1998-1999 }\end{array}$ & $\begin{array}{l}\text { HIV-infected } \\
\text { women } \\
(n=273)\end{array}$ & $\begin{array}{l}\text { HIV-specialist } \\
\text { care vs. } \\
\text { non-HIV-specialist } \\
\text { care. }\end{array}$ & ART use & $\begin{array}{l}\text { HIV-specialist Non-HIV-specialist } \\
\text {-CD4 cell count }<200(P=0.6) \\
\text {-CD4 cell count } 200-500(P \leq 0.001)\end{array}$ & $\begin{array}{l}\text { Self-reported } \\
\text { use of ART. } \\
\text { Analysis } \\
\text { for use of } \\
\text { ART was adjusted } \\
\text { for significant } \\
\text { predictors that } \\
\text { led women to use } \\
\text { HIV-specialist } \\
\text { care. Provider } \\
\text { type based on } \\
\text { self-report by } \\
\text { patients. Data on } \\
\text { types of ART use } \\
\text { were adjusted for } \\
\text { patients' } \\
\text { characteristics. } \\
\text { All other data, } \\
\text { no adjustment } \\
\text { was stated. }\end{array}$ \\
\hline $\begin{array}{l}\text { Horberg } \\
2012 \text { (15) }\end{array}$ & $\begin{array}{c}\text { California, } \\
\text { USA }\end{array}$ & $\begin{array}{c}\text { Retrospective } \\
\text { cohort } \\
\text { analysis. } \\
\text { Data } \\
\text { collected } \\
\text { for years } \\
\text { 1996-2006 }\end{array}$ & $\begin{array}{l}\text { HIV-infected } \\
\text { patients } \\
\text { initiating } \\
\text { a new cART } \\
\text { regimen } \\
(\mathrm{n}=7.071) \\
\text { or initiating a } \\
\text { second or later } \\
\text { cART } \\
\text { (n = 3730) } \\
\text { in an } \\
\text { integrated } \\
\text { healthcare } \\
\text { system }\end{array}$ & $\begin{array}{l}\text { Non-ID/non-HIV- } \\
\text { expert PCP vs. } \\
\text { non-ID but } \\
\text { HIV-expert } \\
\text { PCP vs. ID } \\
\text { specialists vs. } \\
\text { HIV-trained } \\
\text { NP/PA }\end{array}$ & $\begin{array}{c}\text { ART } \\
\text { adherence }\end{array}$ & $\begin{array}{ccc}\begin{array}{c}\text { Non-ID/ } \\
\text { non-HIV } \\
\text { expert }\end{array} \begin{array}{c}\text { HIV } \\
\text { expert }\end{array} & \begin{array}{c}\text { ID } \\
\text { specialist }\end{array} & \begin{array}{c}\text { NP/ } \\
\text { PA }\end{array} \\
\text { Undetectable at } 12 \text { months in: } \\
\text {-ART-naïve patients (adj } P=0.36 \text { ) } \\
\text {-ART-experienced patients (adj } P=0.80 \text { ) }\end{array}$ & $\begin{array}{l}\text { All data were } \\
\text { adjusted for } \\
\text { clustering effect } \\
\text { and patients' } \\
\text { characteristics. } \\
\text { Clinicians with } \\
\text { more HIV } \\
\text { caseload } \\
\text { (adj } P=0.03 \text { ) } \\
\text { and experience } \\
\text { (adj } P=0.003 \text { ) } \\
\text { was significant } \\
\text { in VL success } \\
\text { after } 12 \text { months } \\
\text { of cART } \\
\text { initiation } \\
\text { among } \\
\text { ART-naïve } \\
\text { patients but not } \\
\text { ART-experienced } \\
\text { patients } \\
\text { (caseload: adj } \\
P=0.96 ; \\
\text { experience: adj } \\
P=0.98 \text { ). }\end{array}$ \\
\hline $\begin{array}{c}\text { Landon } \\
2003(16)\end{array}$ & USA & $\begin{array}{c}\text { Prospective } \\
\text { cohort study. } \\
\text { Data } \\
\text { collected } \\
\text { for years } \\
\text { 1998-1999 }\end{array}$ & $\begin{array}{l}\text { Non-institutionaliz } \\
\text { ed HIV } \\
\text { patients } \\
\text { participating } \\
\text { in a research study } \\
(\mathrm{n}=1820) .\end{array}$ & $\begin{array}{c}\text { ID-trained } \\
\text { physicians vs. } \\
\text { GM HIV-expert } \\
\text { physicians vs. } \\
\text { GM } \\
\text { non-HIV-expert } \\
\text { physicians }\end{array}$ & $\begin{array}{l}\text { Appropriate } \\
\text { cART } \\
\text { therapy } \\
\text { at } 12 \& 18 \\
\text { months } \\
\text { after first } \\
\text { protease } \\
\text { inhibitor } \\
\text { approval }\end{array}$ & $\begin{array}{l}\text { ID physician GM HIV-expert } \begin{array}{c}\text { GM } \\
\text { non-H } \\
\text { IV } \\
\text { expert }\end{array} \\
\text {-GM (HIV-expert and non-HIV-expert) vs. } \\
\text { ID physicians: adj OR 0.69, 95\% CI } 0.52 \text { to } \\
\text { 0.95 } \\
\text {-non-HIV-expert GM vs. ID physicians: adj } \\
\text { OR 0.32, 95\% CI 0.17 to 0.61 } \\
\text {-HIV-expert GM vs. ID physicians: adj OR } \\
\text { 0.80, 95\% CI 0.59 to } 1.10 . \\
\text {-Low-volume physicians vs. high-volume } \\
\text { physicians OR 0.26, 95\% CI } 0.14 \text { to } 0.48\end{array}$ & $\begin{array}{l}\text { All data were } \\
\text { adjusted for } \\
\text { patients' } \\
\text { characteristics. }\end{array}$ \\
\hline
\end{tabular}




\section{Continued}

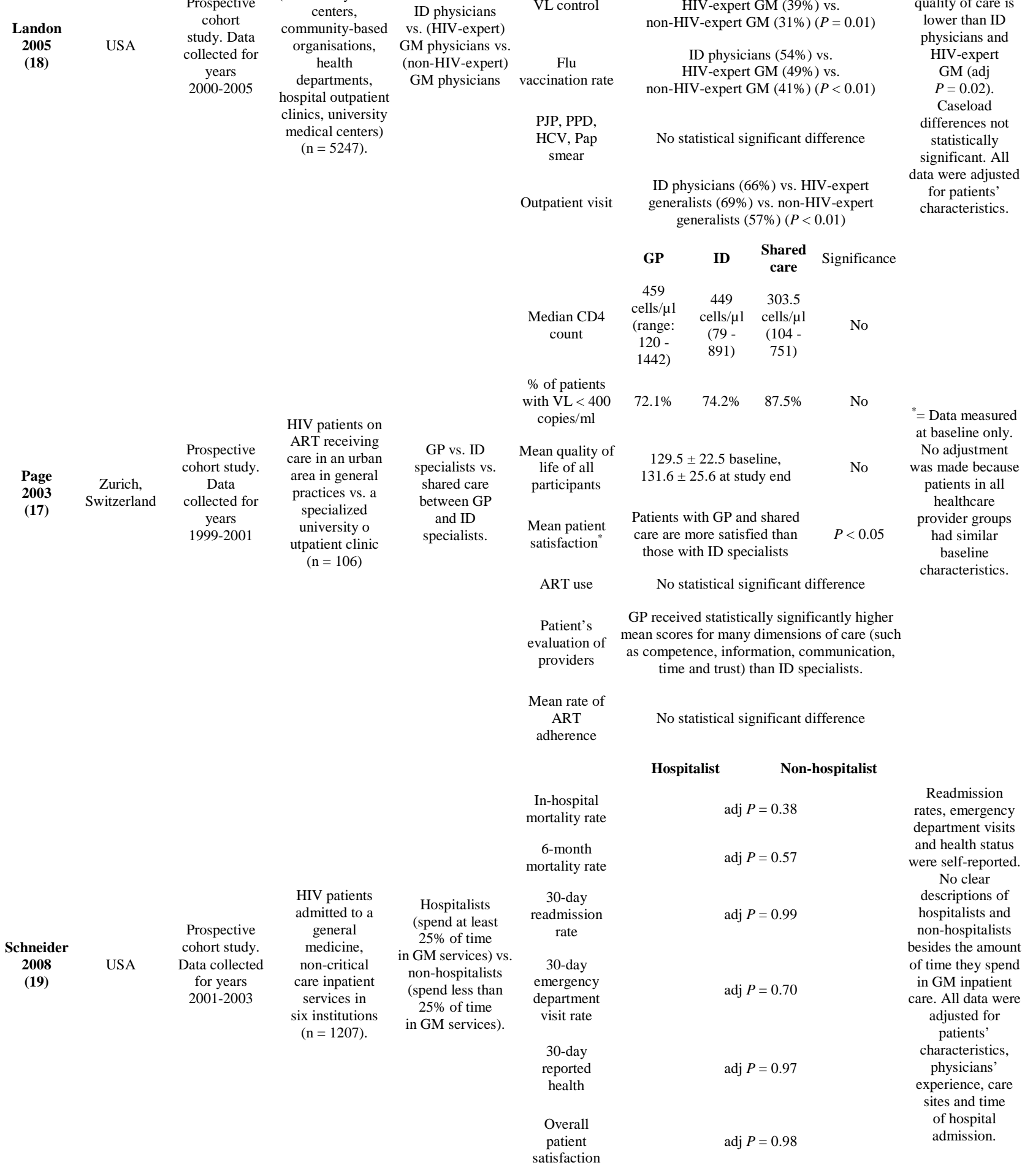




\section{Continued}

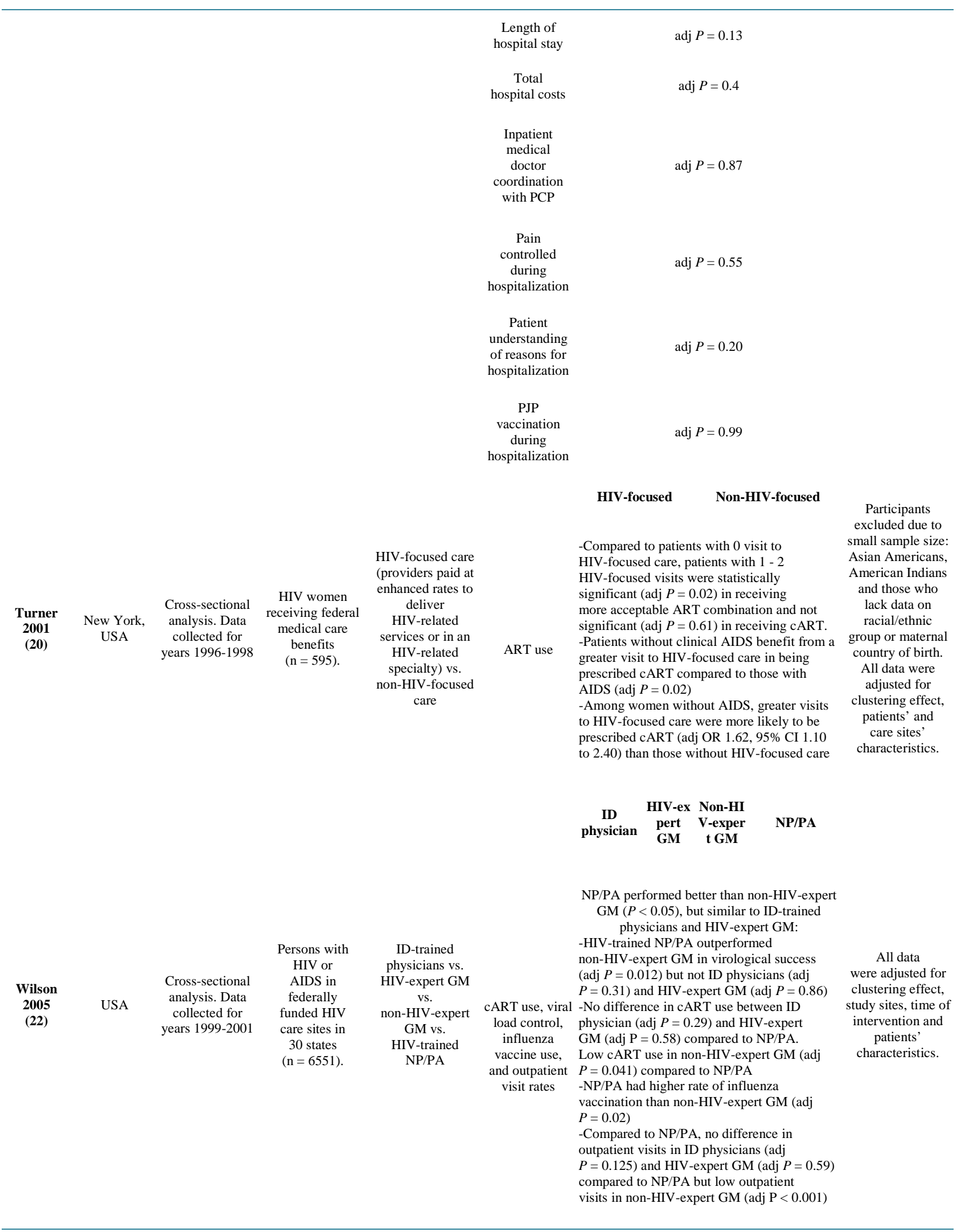




\section{Continued}

\begin{tabular}{|c|c|}
\hline $\begin{array}{c}\text { PJP } \\
\text { prophylaxis } \\
\text { and HCV } \\
\text { testing }\end{array}$ & $\begin{array}{l}\text { NP/PA vs. GM physicians no } \\
\text { statistical significant difference }\end{array}$ \\
\hline PPD testing & $\begin{array}{c}\text { Compared to NP/PA (rate }=0.63 \text { ), ID } \\
\text { physicians (rate }=0.53 \text {; adj } P=0.007 \text { ), } \\
\text { HIV-expert GM (rate }=0.47 \text {; adj } P<0.001 \text { ) } \\
\text { and non-HIV-expert GM } \\
\text { (rate }=0.49 \text {; adj } P=0.007 \text { ) }\end{array}$ \\
\hline $\begin{array}{l}\text { Pap smear } \\
\text { testing }\end{array}$ & $\begin{array}{l}\text { Compared to NP/PA (rate }=0.71 \text { ), ID } \\
\text { physicians (rate }=0.56 \text {; adj } P=0.001 \text { ), } \\
\text { HIV-expert GM (rate }=0.62 \text {; adj } P=0.025 \text { ) } \\
\text { and non-HIV-expert GM } \\
\text { (rate }=0.52 \text {; adj } P=0.004 \text { ) }\end{array}$ \\
\hline
\end{tabular}

Notes: Adj $=$ Adjustment or adjusted. ART=Antiretroviral therapy. cART $=$ Combination antiretroviral therapy. $\mathrm{CI}=\mathrm{Confidence}$ interval. GM $=\mathrm{General}$ medicine. GP = General practitioners. HCV $=$ Hepatitis C virus. HIV = Human immunodeficiency virus. ID = Infectious disease. NP = Nurse practitioners. OR = Odds ratio. $P=P$-value. $\mathrm{PA}=$ Physician assistants. $\mathrm{PCP}=$ Primary care providers. $\mathrm{PJP}=$ Pneumocystis jiroveci pneumonia. $\mathrm{PPD}=\mathrm{Purified}$ protein derivatives. USA = United States of America. VL = Viral load. In all included studies, the level of statistical significance was set at $5 \%$, with a p-value of $\leq 0.05$ indicating a statistically significant result.

Table 2. Summary of the quality assessment of the included studies*.

\begin{tabular}{|c|c|c|c|c|c|c|c|}
\hline Study & $\begin{array}{c}\text { Minimizing } \\
\text { selection } \\
\text { bias }^{1}\end{array}$ & $\begin{array}{l}\text { Study } \\
\text { design }^{1}\end{array}$ & $\begin{array}{c}\text { Control of } \\
\text { confounders }^{1}\end{array}$ & Blinding $^{1}$ & \begin{tabular}{c}
\multicolumn{1}{c}{ Data } \\
collection \\
methods $^{1}$
\end{tabular} & Attrition $^{1}$ & $\begin{array}{l}\text { Overall } \\
\text { rating }^{2}\end{array}$ \\
\hline Chu 2010 (14) & Moderate & Moderate & Strong & Moderate & Strong & Strong & Strong \\
\hline Gardner 2002 (21) & Strong & Weak & Strong & Moderate & Weak & NA & Weak \\
\hline Horberg 2012 (15) & Strong & Moderate & Strong & Moderate & Strong & NA & Strong \\
\hline Landon 2003 (16) & Moderate & Moderate & Strong & Moderate & Strong & Strong & Strong \\
\hline Landon 2005 (18) & Moderate & Moderate & Strong & Moderate & Strong & Strong & Strong \\
\hline Page 2003 (17) & Moderate & Moderate & Strong & Moderate & Strong & Strong & Strong \\
\hline Schneider 2008 (19) & Moderate & Moderate & Strong & Moderate & Strong & Weak & Moderate \\
\hline Turner 2001 (20) & Moderate & Weak & Strong & Moderate & Strong & Strong & Moderate \\
\hline Wilson 2005 (22) & Moderate & Weak & Strong & Strong & Strong & NA & Moderate \\
\hline
\end{tabular}

Notes: *Quality of the study was assessed using the effective public health practice project quality assessment tool for quantitative studies (11). NA = Not applicable. ${ }^{1}$ Overall rating: "Strong" = no weak rating, "Moderate" = 1 weak rating and "Weak" = $\geq 2$ weak ratings on the different components of EPHPP Tool. ${ }^{2}$ Parameters assessed: minimization of selection bias: strong, the participants were likely; moderate, somewhat likely; weak, not likely, to represent the target population. Study design: strong, randomization occurred, e.g. RCTs; moderate, study described as case control, before and after, etc.; weak, study design not specified. Confounders: strong, controlled for all relevant confounders; moderate, controlled for some confounders; weak, control for confounders not specified. Blinding: strong, the researchers do not know participants' intervention group and the participants do not know the research question; moderate, the researchers do not know participants' intervention status or the participants do not know the research question or blinding is not stated in the article; weak, the researchers know participants' intervention group and the participants know the research hypothesis. Data collection method: strong, valid and reliable data collection tools; moderate, tools valid but not reliable; weak, validity and reliability not described. Withdrawals and dropouts (attrition): strong, reported withdrawals and dropouts ( $80 \%-100 \%$ of participants completed the study); moderate, reported withdrawals and dropouts (60\% of participants completed the study); weak, withdrawal and dropout rates not specified.

Table 3. Summary of potential confounders controlled for in the included studies.

\begin{tabular}{|c|c|c|c|c|c|c|}
\hline \multirow{2}{*}{ Study } & \multicolumn{6}{|c|}{ Potential confounders controlled for in the study } \\
\hline & Age & Sex & Race/ethnicity & HIV risk & Insurance status & Case mix \\
\hline Chu 2010 (14) & Yes & Yes & Yes & Yes & Yes & Yes \\
\hline Gardner 2002 (21) & Yes & NA & No & Yes & Yes & Yes \\
\hline Horberg 2012 (15) & Yes & Yes & Yes & Yes & NA & Yes \\
\hline Landon 2003 (16) & Yes & Yes & Yes & Yes & Yes & Yes \\
\hline Page 2003 (17) & \multicolumn{6}{|c|}{ NA —-same baseline characteristics for patients in different intervention arms } \\
\hline Schneider 2008 (19) & Yes & Yes & Yes & No & Yes & Yes \\
\hline Turner 2001 (20) & Yes & NA & Yes & No & NA & Yes \\
\hline Wilson 2005 (22) & Yes & Yes & No & Yes & NA & Yes \\
\hline
\end{tabular}

Note: NA = Not applicable. 
Table 4. Summary of included studies’ outcome measurements.

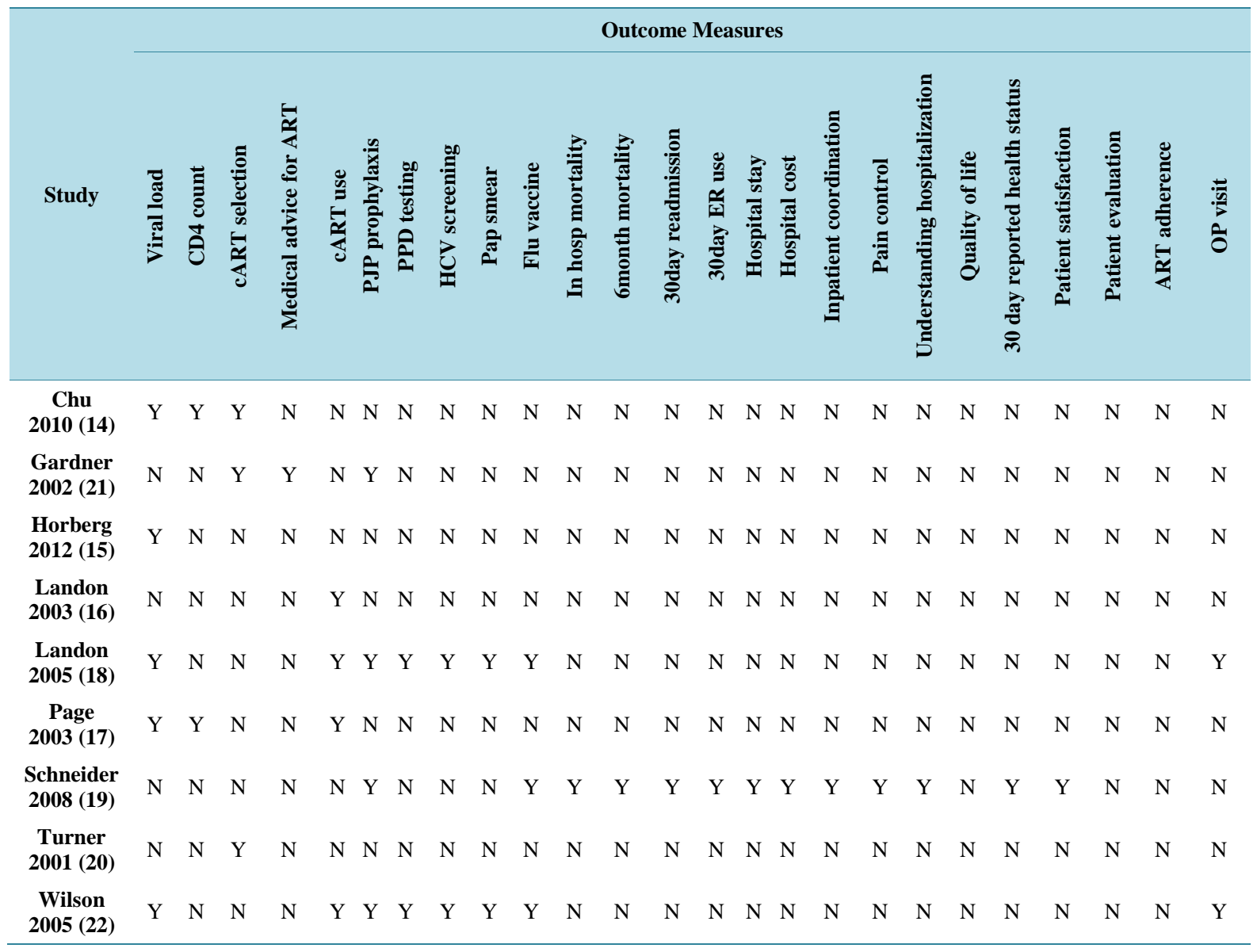

Notes: "Y" = Measurement included in the study. "N" = No measurement. ART = Antiretroviral therapy; cART = Combination antiretroviral therapy; $\mathrm{ER}=$ Emergency room; HCV = Hepatitis C virus; HIV = Human immunodeficiency virus; OP = Outpatient; PJP = Pneumocystis jiroveci pneumonia; $\mathrm{PPD}=$ Purified protein derivatives.

In the study by Horberg et al. [15], while there was no statistical difference in virologic success between ART-naïve $(P=0.36)$ and ART-experienced patients $(P=0.80)$ treated by non-infectious diseases (ID)/nonHIV-expert primary care providers (PCP), non-ID/HIV-expert PCP, ID specialists and HIV-trained nurse practitioner (NP) or physician assistant (PA) after 12 months of cART initiation, more ART-naïve patients under clinicians with more HIV caseload $(P=0.03)$ and HIV experience $(P=0.003)$ were able to achieve virologic success.

Landon et al., [18] observed that ID physicians and HIV-expert generalists were better at controlling patients' viral load than non-HIV-expert generalists $(P<0.001)$. After controlling for providers' specialty training, HIV caseload and knowledge, the study still showed that patients under non-HIV-expert generalists had lower rates of virologic success than other clinicians within the study. However, the study found no significant difference in the outcome between the different clinicians when looking at HIV caseload alone.

Additionally, Wilson and colleagues [22] found that HIV-trained NP and PA performed better in viral load control than non-HIV-expert generalists, but comparable to ID physicians and HIV-expert generalists.

\subsubsection{CD4 Cell Count}

Two studies [14] [17] measured CD4 cell count. Chu et al., [14] found no significant difference in achieving immunologic success among patients cared for by non-HIV-expert PCP in collaboration with HIV specialists and ID clinicians with NP or PA (OR $=0.76$, 95\% CI 0.47 to 1.21). Page et al., [17] also found no statistical difference in the median CD4 cell count between patients cared for by general practitioner (GP) actively treating HIV patients in their practices, ID specialists and those in shared care (i.e. patients who were seeing both specialists and GP at the same time) over a one-year period. 


\subsubsection{Antiretroviral Therapy}

Seven studies [14] [16]-[18] [20]-[22] measured various ART-related outcomes such as selection of cART and medical advice for ART.

Two studies found that patients cared for by clinicians without HIV-related training or experience were less likely to be on cART (OR $=0.32,95 \%$ CI 0.17 to 0.61 ), [16] and less likely to receive cART $(P<0.001)$, [18] when compared to clinicians with HIV-related training and experience and/or clinicians without HIV-related training and experience collaborating with those with HIV-related expertise.

Furthermore, Wilson et al., [22] observed lower cART use among patients under non-HIV-expert generalists when compared to those under HIV-trained NP and PA, who had similar rate of cART use as HIV-expert generalists' and ID physicians' patients.

Turner et al., [20] reported that women with HIV-focused care visits, defined as visits to clinicians who were paid at a higher rate to provide HIV-related services or those in an HIV-related specialty were more likely to receive acceptable ART combinations than those not receiving any HIV-focused care (Table 1). However, when stratifying patients into those with AIDS and those without, the study authors found that women without AIDS benefitted from greater visits to HIV-focused care than those with AIDS $(P=0.02)$. Nonetheless, among women without AIDS, three or more HIV-focused care visits was associated with appropriate cART use compared to those without HIV-focused care visit (OR = 1.62, 95\% CI 1.10 to 2.40$)$.

Similarly, Gardner et al., [21] observed that more patients who self-reported to attend HIV-specialist clinics received advice to begin ART $(P<0.001)$ and received appropriate cART and non-cART (monotherapy or combination ART without protease inhibitor or non-nucleoside reverse transcriptase inhibitor) $(P<0.001)$ than those attending non-HIV-specialist clinics. Yet, the level of significance was only observed in patients with CD4 cell count between 200 and 500 cells $/ \mathrm{mm}^{3}$ ( $P<0.001$ and $P=0.009$, respectively). In this study, attending HIV specialist clinics did not necessarily mean that patients received care from HIV specialists.

\subsubsection{Opportunistic Infection Prophylaxis}

Four studies, [18] [19] [21] [22] had outcome measurements associated with opportunistic infection prophylaxis.

All four studies measured the use of Pneumocystis jiroveci pneumonia (PJP) prophylaxis and found no differences in its use between ID physicians, HIV-expert generalists and non-HIV-expert generalists [18]; hospitalists and non-hospitalists $(P=0.99)$ [19]; HIV-specialist and non-HIV-specialist clinics for women who had CD4 cell counts less than 100 cells $/ \mathrm{mm}^{3}(P=0.19)$ [21]; and ID physicians, HIV-expert generalists, non-HIV-expert generalists and HIV-trained NP or PA [22].

Two studies measured hepatitis $\mathrm{C}$ screening but did not find any difference between ID physicians, HIV-expert generalists and non-HIV-expert generalists [18], and ID physicians, HIV-expert generalists, non-HIV-expert generalists and HIV-trained NP or PA [22].

Additionally, Landon et al., [18] did not find any difference in the use of purified protein derivatives (PPD) testing for tuberculosis, hepatitis $\mathrm{C}$ screening and Pap smear among different clinicians. However, the study authors found that ID physicians and HIV-expert generalists significantly provided more influenza vaccination to their patients than non-HIV-expert generalists $(P<0.01)$.

Wilson et al., [22] however found that HIV-trained NP or PA outperformed ID physicians, HIV-expert generalists and non-HIV-expert generalists in PPD testing of their patients and providing Pap smear. The same study found that patients cared for by HIV-trained NP or PA had significantly higher rate of influenza vaccination than patients under the care of non-HIV-expert generalists $(P=0.02)$.

\subsubsection{Hospital Care and Costs}

Only one study, [19] measured hospital-related care and costs and found no significant differences in all outcome measurements between HIV patients under the care of hospitalists and non-hospitalists (Table 1), including the rate of in-hospital mortality (rate $=-1.7 \%, 95 \% \mathrm{CI}-1.8$ to $-1.5, P=0.38$ ) and six-month mortality rate $-1.6 \%, 95 \%$ CI -1.7 to $-1.5, P=0.57)$.

\subsubsection{Psychosocial Outcome}

Two studies [17] [19] measured patients' psychosocial outcomes such as quality of life and patient satisfaction.

Page et al., [17] did not find any difference in patients' mean quality of life between patients who were cared 
for by GP actively treating HIV patients, ID specialists and shared care after 12 months of care. Yet, compared to patients cared for by ID specialists, patients with GP $(P<0.05)$ and shared care $(P<0.05)$ had significantly higher patient satisfaction.

Schneider et al., [19] observed no significant difference in 30-day self-reported health status (rate $=-0.2 \%$, $95 \% \mathrm{CI}-0.2$ to $-0.2, P=0.97)$ and overall patients' self-rated satisfaction $(-0.1 \%, 95 \% \mathrm{CI}-0.1$ to $-0.7, P=$ 0.98 ) between patients under the care of hospitalists and non-hospitalists.

\subsubsection{Behavioural Outcome}

Four studies [15] [17] [18] [22] assessed patients’ ART adherence or outpatient visits.

\subsection{ART Adherence}

Horberg et al., [15] found no significant difference in ART adherence in ART-naïve patients $(P=0.97)$ and ART-experienced patients $(P=0.66)$ under the care of non-ID/non-HIV-expert PCP, non-ID/HIV-expert PCP, ID specialists and HIV-trained NP or PA. In addition, Page et al., [17] observed no significant difference in ART adherence between patients who received care from GP actively treating HIV patients, ID specialists or shared care.

\subsection{Outpatient Visit}

Landon et al., [18] found that patients receiving care from ID physicians or HIV-expert generalists had significantly greater outpatient visits than patients under the care of non-HIV-expert generalists $(P<0.01)$. Additionally, Wilson et al., [22] observed that outpatient visit rates among ID physicians, HIV-expert generalists and HIV-trained NP or PA were comparable. However, patients under HIV-trained NP or PA had significantly higher rate of outpatient visits than those under non-HIV-expert generalists $(P<0.001)$.

\section{Non-HIV Related Outcomes and cART Interactions}

None of the included studies reported any outcome related to medication errors, adverse drugs reactions and chronic diseases associated with long-term HIV care.

\section{Discussion}

While some studies included in this review have shown small differences in some outcomes, no conclusive evidence was identified about relative benefits and risks' regarding which specific type of healthcare provider was better at providing medical care to PLWHA. Yet, HIV patients who were cared for by HIV-expert healthcare providers (through accredited training or self-identification) and those who have HIV-related specialty (e.g. infectious disease) tend to achieve better virologic, immunologic and ART-related outcomes. When HIV patients were cared for by non-HIV-expert healthcare providers, the key to achieving successful outcomes was collaboration with HIV-expert clinicians or ID specialists. None of the included studies observed that healthcare providers with HIV expertise or HIV-related training performed poorer in the measured outcomes than clinicians without HIV-related expertise or specialty.

There is not enough evidence in this review to suggest that HIV care providers with greater caseloads-a proxy for experience-have better outcomes and improved patient survival [12]. For instance, Horberg et al., [15] observed that healthcare providers' HIV experiences only influenced patients' virologic success in ART-naïve patients and did not affect ART adherence in both ART-naïve and ART-experienced patients. Additionally, Landon et al., [18] found caseload to cause no effect on any of their eight quality-of-care measures. On the other hand, after adjusting for clinicians' training and HIV expertise, Landon et al., [16] observed patients under the care of clinicians with lower HIV caseload had lower odds of being on cART 12 months after the approval of the first protease inhibitor and no significant effects 18 months after. These mixed results could be attributed to the complexities of ART regimen in which healthcare providers with more HIV-related experience were better informed than their less experienced colleagues. Yet, some of these findings, as observed in Landon et al., [16] indicate that over time generalists are able to develop expertise specifically around ART that is comparable to that of specialists.

Findings from this review were observed to agree with a review by Rackal et al., [13] which examined the ef- 
fects of providers' training and experience on the quality of HIV care. In their review, they found that patients cared for by clinicians with HIV training or expertise had better medical and social outcomes than patients under clinicians without any HIV training or expertise. However, the authors were unable to find any association between the quality of care and providers' HIV experience.

Furthermore, evidence from this review shows that quality of care, adherence to treatment, [15] and use of cART, [16] [18] were not affected by the caseload or experience of the provider. This is in contrast to the findings by Handford et al., [12] who found that HIV clinicians' with higher number of patients or greater experience with HIV patients had higher use of cART and decreased patients' mortality. This contrast could be attributed to different care settings and level of HIV experience considered in the reviews.

This systematic review has some important limitations. Only two of the included studies were published in the preceding five years and HIV care and treatment has evolved rapidly since then. No study reported on non-HIV related outcomes and cART interactions with other drugs even though these outcomes present major challenges particularly in older PLWHA with co-morbidities. Additionally, due to the small number of studies, their observational nature and the heterogeneity of the interventions and quality of care outcomes, a meta-analysis could not be performed. It is also important to note that in some of these studies, a small number of the outcome measurements were self-reported, mainly ART adherence and outpatient visits. In some studies, clinicians' HIV expertise was self-reported and was not confirmed by the study authors [16] [18] [22]. However, in this review we explicitly stated which outcomes or clinicians were self-reported. Furthermore, all but one of the included studies were conducted in the USA [17]. As HIV specialist training and health systems are different in many developed countries, including within the USA itself, evidence observed in this review needs to be interpreted with caution especially when applying such findings to other settings with different healthcare systems, training and social health coverage. In spite of these limitations, most of the studies had adequate controls for important confounding variables associated with patient and provider characteristics and most of the studies were of high quality.

\section{Conclusions}

In summary, this review provides some evidence for healthcare providers and policy makers to consider when providing medical care to PLWHA. Clinicians without HIV-related expertise or specialty were observed to perform poorer in some important dimensions of HIV care such as viral load control and use of cART.

Therefore, it is pertinent that clinicians who have limited HIV knowledge or expertise of caring for PLWHA should seek to gain more HIV knowledge and expertise or work in collaboration with HIV-trained clinicians and experts.

More high quality studies to assess the effectiveness of HIV care and treatment provided by different healthcare providers in developed countries are needed. Such studies should examine not only the virological or immunological outcomes of HIV care and treatment, but also other clinical outcomes relating to medication errors, knowledge of drug interactions and patient's quality of life.

\section{Conflict of Interest}

None declared.

\section{Fund}

None declared.

\section{References}

[1] Soloway, B. (1997) Primary Care and Specialty Care in the Age of HAART. http://www.jwatch.org/ac199705010000001/1997/05/01/primary-care-and-specialty-care-age-haart

[2] British HIV Association (BHIVA) (2013) Standards of Care for People Living with HIV. http://www.bhiva.org/documents/Standards-of-care/BHIVAStandardsA4.pdf

[3] Deeks, S.G., Lewin, S.R. and Havlir, D.V. (2013) The End of AIDS: HIV Infection as a Chronic Disease. The Lancet, 382, 1525-1533. http://dx.doi.org/10.1016/S0140-6736(13)61809-7

[4] World Health Organisation (2014) March 2014 Supplement to the 2013 Consolidated Guidelines on the Use of Antire- 
troviral Drugs for Treating and Preventing HIV Infection: Recommendations for a Public Health Approach. http://apps.who.int/iris/bitstream/10665/104264/1/9789241506830_eng.pdf

[5] Kredo, T., Adeniyi, F.B., Bateganya, M. and Pienaar, E.D. (2014) Task Shifting from Doctors to Non-Doctors for Initiation and Maintenance of Antiretroviral Therapy. Cochrane Database of Systematic Reviews, Article No.: CD007331. http://dx.doi.org/10.1002/14651858.CD007331.pub3

[6] Kredo, T., Ford, N., Adeniyi, F.B. and Garner, P. (2013) Decentralising HIV Treatment in Lower- and Middle-Income Countries. Cochrane Database of Systematic Reviews, Article No.: CD009987. http://dx.doi.org/10.1002/14651858.CD009987.pub2

[7] Centre for Reviews and Dissemination (2009) Systematic Reviews: CRD's Guidance for Undertaking Reviews in Health Care. University of York, York.

[8] Catumbela, E., Certal, V., Freitas, A., et al. (2013) Definition of a Core Set of Quality Indicators for the Assessment of HIV/AIDS Clinical Care: A Systematic Review. BMC Health Services Research, 13, 236. http://dx.doi.org/10.1186/1472-6963-13-236

[9] The Cochrane Library (2014) About the Cochrane Library. http://www.thecochranelibrary.com/view/0/AboutTheCochraneLibrary.html

[10] Higgins, J.P.T. and Green, S., Eds. (2011) Cochrane Handbook for Systematic Reviews of Interventions Version 5.1.0 [Updated March 2011]. The Cochrane Collaboration. www.cochrane-handbook.org

[11] Effective Public Health Practice Project, EPHPP (2009) Quality Assessment Tool for Quantitative Studies. http://www.ephpp.ca/tools.html

[12] Handford, C., Tynan, A.M., Rackal, J.M. and Glazier, R. (2006) Setting and Organization of Care for Persons Living with HIV/AIDS. Cochrane Database of Systematic Reviews, Article No.: CD004348. http://dx.doi.org/10.1002/14651858.CD004348.pub2

[13] Rackal, J.M., Tynan, A.M., Handford, C.D., Rzeznikiewiz, D., Agha, A. and Glazier, R. (2011) Provider Training and Experience for People Living with HIV/AIDS. Cochrane Database of Systematic Reviews, Article No.: CD003938. http://dx.doi.org/10.1002/14651858.CD003938.pub2

[14] Chu, C., Umanski, G., Blank, A., Grossberg, R. and Selwyn, P.A. (2010) HIV-Infected Patients and Treatment Outcomes: An Equivalence Study of Community-Located, Primary Care-Based HIV Treatment vs. Hospital-Based Specialty Care in the Bronx, New York. AIDS Care-Psychological and Socio-Medical Aspects of AIDS/HIV, 22, 15221529. http://dx.doi.org/10.1080/09540121.2010.484456

[15] Horberg, M.A., Hurely, L.B., Towner, W.J., Allerton, M.W., Tang, B.T., Catz, S.L., et al. (2012) Influence of Provider Experience on Antiretroviral Adherence and Viral Suppression. HIV/AIDS—Research and Palliative Care, 4, 125-133. http://dx.doi.org/10.2147/HIV.S35174

[16] Landon, B.E., Wilson, I.B., Cohn, S.E., Fichtenbaum, C.J., Wong, M.D., Wenger, N.S., et al. (2003) Physician Specialization and Antiretroviral Therapy for HIV: Adoption and Use in a National Probability Sample of Persons Infected with HIV. Journal of General Internal Medicine, 18, 233-241. http://dx.doi.org/10.1046/j.1525-1497.2003.20705.X

[17] Page, J., Weber, R., Somaini, B., Nostlinger, C., Donath, K. and Jaccard, R., the SESAM Study Group (2003) Quality of Generalist vs. Specialty Care for People with HIV on Antiretroviral Treatment: A Prospective Cohort Study. HIV Medicine, 4, 276-286. http://dx.doi.org/10.1046/j.1468-1293.2003.00157.x

[18] Landon, B.E., Wilson, I.B., McInnes, K., Landrum, M.B., Hirschhorn, L.R., Marsden, P.V. and Cleary, P.D. (2005) Physician Specialization and the Quality of Care for Human Immunodeficiency virus Infection. Archives of Internal Medicine, 165, 1133-1139. http://dx.doi.org/10.1001/archinte.165.10.1133

[19] Schneider, J.A., Zhang, Q., Auerbach, A., Gonzales, D., Kaboli, P., Schnipper, J., et al. (2008) Do Hospitalists or Physicians with Greater Inpatient HIV Experience Improve HIV Care in the Era of Highly Active Antiretroviral Therapy? Results from a Multicenter Trial of Academic Hospitalists. Clinical Infectious Diseases, 46, 1085-1092. http://dx.doi.org/10.1086/529200

[20] Turner, B.J., Zhang, D.Z., Laine, C., Pomerantz, R.J., Cosler, L. and Hauck, W.W. (2001) Association of Provider and Patient Characteristics with HIV-Infected Women's Antiretroviral Therapy Regimen. JAIDS: Journal of Acquired Immune Deficiency Syndromes, 27, 20-29. http://dx.doi.org/10.1097/00126334-200105010-00004

[21] Gardner, L.I., Holmberg, S.D., Moore, J., Arnsten, J.H., Mayer, K.H., Rompalo, A., et al. (2002) Use of Highly Active Antiretroviral Therapy in HIV-Infected Women: Impact of HIV Specialist Care. JAIDS: Journal of Acquired Immune Deficiency Syndromes, 29, 69-75. http://dx.doi.org/10.1097/00042560-200201010-00010

[22] Wilson, I.B., Landon, B.E., Hirschhorn, L.R., McInnes, K., Ding, L., Marsden, P.V. and Cleary, P.D. (2005) Quality of HIV Care Provided by Nurse Practitioners, Physician Assistants, and Physicians. Annals of Internal Medicine, 143, 729-736. http://dx.doi.org/10.7326/0003-4819-143-10-200511150-00010 


\section{Abbreviations and Acronyms}

ART = antiretroviral therapy;

cART = combination antiretroviral treatment;

$\mathrm{CI}=$ confidence interval;

$\mathrm{GP}=$ general practitioner;

HIV = human immunodeficiency virus;

ID = infectious disease;

LMICS = low and middle-income countries;

$\mathrm{NP}=$ nurse practitioner;

OECD = Organisation for Economic Cooperation and Development;

$\mathrm{PA}=$ physician assistant;

$\mathrm{PCP}=$ primary care provider;

PJP = Pneumocystic jiroveci pneumonia;

PLWHA = people living with HIV/AIDS;

$\mathrm{PPD}=$ purified protein derivatives. 